\title{
Bimodal Porous Carbon as a Negative Electrode Material for Lithium-Ion Capacitors
}

\author{
Sang-Wook Woo, ${ }^{a}$ Kaoru DokKo,, ${ }^{\mathrm{a}, \mathrm{b}}$ Hiroyuki NaKano, ${ }^{\mathrm{a}, \mathrm{b}}$ and Kiyoshi KanamURA ${ }^{\mathrm{a}, \mathrm{b}}$ * \\ ${ }^{a}$ Department of Applied Chemistry, Graduate School of Urban Environmental Science, Tokyo Metropolitan \\ University (1-1 Minami-ohsawa, Hachioji, Tokyo 192-0397, Japan) \\ b CREST, Japan Science and Technology Agency (4-1-8 Honcho, Kawaguchi, Saitama 332-0012, Japan)
}

Received January 31, 2007 ; Accepted May 1, 2007

\begin{abstract}
Bimodal porous carbons consisting of interconnected macropores and spherical mesopores, were prepared by colloidal crystal templating method. The template was prepared by evaporation process of suspensions containing monodisperse poly[styrene-(co-2-hydroxyethyl methacrylate)] (PSHEMA) latex and colloidal silica in water. The carbonization of PSHEMA at $1000^{\circ} \mathrm{C}$ under inert atmosphere provided very thin carbon layer on the colloidal silica in the template, and the macropore corresponding to the PSHEMA particle size were formed simultaneously. After this procedure, bimodal porous carbons were obtained by removing the silica particles with hydrofluoric acid. Three kinds of bimodal porous carbons were prepared using PSHEMA latex of $450 \mathrm{~nm}$ and colloidal silica with three different average diameters of $10 \sim 20 \mathrm{~nm}, 40 \sim 50 \mathrm{~nm}$, and $70 \sim 100 \mathrm{~nm}$, respectively. Bimodal porous structure was observed with a field emission-scanning electron microscope. Nitrogen adsorption/desorption measurements revealed that the prepared samples involved macropore and mesopore with small amount of micropore. The bimodal porous carbons were electrochemically evaluated as a negative electrode of lithium-ion capacitor in ethylene carbonate and diethyl carbonate containing $1 \mathrm{~mol} \mathrm{dm}^{-3} \mathrm{LiClO}_{4}$. The bimodal porous carbon prepared using silica of $10 \sim 20 \mathrm{~nm}$ showed a large capacitance of $360 \mathrm{~F} \mathrm{~g}^{-1}$ at a high current density of $7.4 \mathrm{~A} \mathrm{~g}^{-1}$.
\end{abstract}

Key Words : Lithium-ion Capacitors, Lithium-ion Batteries, Colloidal Crystal, Macroporous Carbon

\section{Introduction}

Nonaqueous Li-ion capacitors (LICs) have been developed by several research groups. ${ }^{1-8)}$ In the LIC, Li-ion intercalation and deintercalation take place at the negative electrode during charge and discharge as in lithium battery, while anion adsorption and desorption occur at the positive electrode surface as in electric double-layer capacitor (EDLC). The positive electrode of LIC is activated carbon, and Li-intercalation compounds such as carbonaceous materials and $\mathrm{Li}_{4} \mathrm{Ti}_{5} \mathrm{O}_{12}$ have been proposed as negative electrode materials. ${ }^{1-5)}$ The capacity and operating voltage of the LIC are higher than those of conventional EDLCs. The improvement of rate capability of negative electrode will further enhance the power density of LIC. The large specific surface area (SSA) of negative electrode will provide a large electrochemical interface, which will reduce the charge transfer resistance of Li-intercalation. Indeed, Amatucci et al. have proposed nanostructured $\mathrm{Li}_{4} \mathrm{Ti}_{5} \mathrm{O}_{12}$ as an anode material ${ }^{1-3)}$ and Yoshino et al. have reported that pre-lithiated activated carbon can deliver a large capacity. ${ }^{4)}$ In general, the porous structures of commercialized activated carbons are complicated and involved with macropores $(>50 \mathrm{~nm})$, mesopores, and micropores $(<2 \mathrm{~nm})$. The large SSA of activated carbon is attributed to micropores and mesopores. By the way, the sizes of solvated ion species are as large as micropore size, for example, the diameter of solvated $\mathrm{Li}^{+}$in propylene carbonate is as large as $0.82 \mathrm{~nm} .^{9)}$ So, it is difficult to utilize all of the micropores of activated carbon for electrochemical inter- face in nonaqueous electrolytes. It has been also pointed out that not only mesopores but also macropores are important for the penetration of electrolyte to microporous structure and the mobility of ions in the pores.9) Therefore, it is important for the power density of LIC to control the meso- and macro-porous structures of carbon negative electrode.

Mesoporous carbons can be prepared by several methods such as templating ${ }^{10)}$ and colloidal imprinting processes. $^{11)}$ Recently, we have successfully prepared 3D ordered macroporous carbon having walls composed of hollow mesosized spheres, ${ }^{12)}$ and we call this carbon "bimodal porous carbon". This novel porous carbon can be prepared by colloidal crystal templating method. The colloidal crystal consisting of monodisperse large polymer particles and small silica particles were used as a hard template. The sizes of macoropore and mesopore of the resulting carbon could be controlled by choosing the sizes of polymer and silica particle, respectively. The prepared bimodal porous carbon had interconnected macropores and high specific surface area due to the mesoporous walls. In this work, the electrochemical properties of the bimodal porous carbon were investigated as a negative electrode material for LICs.

\section{Experimental}

\section{1 Preparation of bimodal porous carbon}

The detailed preparation method of bimodal porous carbon was described elsewhere. ${ }^{12)}$ Monodisperse poly[styrene-(co-2-hydroxyethyl methacrylate)] (PSHE- 
MA) latex and silica colloids were utilized to prepare the template. PSHEMA latex was synthesized by batch surfactant-free emulsion copolymerization of styrene and 2hydroxyethyl methacrylate following the procedure reported by Reese and Asher. ${ }^{13)}$ The diameter of the prepared PSHEMA particle was $450 \mathrm{~nm}$ confirmed by scanning electron microscope observation. Three kinds of silica colloids CS100, CS50, and CS20, which had average diameters of $70 \sim 100 \mathrm{~nm}, 40 \sim 50 \mathrm{~nm}$, and $10 \sim 20$ $\mathrm{nm}$, respectively (Snowtex ${ }^{\circledR}$, supplied from Nissan Chemical Industries Ltd.), were used as received.

Monodisperse PSHEMA latex and the silica particles were uniformly mixed in deionized water by an ultrasonic treatment. Water in the mixed suspension was simply evaporated in Petri dish at $60^{\circ} \mathrm{C}$ for 24 hours, and the PSHEMA-silica composite was accumulated on the bottom of the Petri dish. During the evaporation, the monodisperse PSHEMA spheres self-assembled into an ordered lattice where the silica particles were forced to pack closely at the interstices between the PSHEMA spheres. Thus, two types of colloids with significantly different sizes were utilized to create a macrosized polymeric colloidal crystal with voids filled with mesosized small silica colloids. The volume ratio of PSHEMA and silica in the composite was controlled to be $74: 26$, which allowed the PSHEMA spheres to form close-packed lattice in the composite. In this way, a PSHEMA-silica composite membrane ( $130 \mu \mathrm{m}$ thick) was obtained. The obtained PSHEMA-silica composite was treated at high temperatures in a horizontal furnace under dry argon flows (30 $\mathrm{mL} \mathrm{min}^{-1}$ flow rate) to carbonize PSHEMA particles. The temperature was increased from room temperature to $1000{ }^{\circ} \mathrm{C}$ at a heating rate of $4 \mathrm{~K} \mathrm{~min}^{-1}$ and then cooled to room temperature. After the carbonization of PSHEMA, the silica particles were removed with $20 \%$ aqueous hydrofluoric acid, and the resulting porous carbons were washed with ultra pure water and dried in a vacuum oven at $110^{\circ} \mathrm{C}$. Through this procedure, a membrane $(5 \mathrm{~mm} \times 5 \mathrm{~mm})$ of bimodal porous carbon was obtained. The porous carbon membranes prepared using silica colloids CS100, CS50, and CS20 hereafter will be denoted as sample A, B, and C, respectively. The thickness and mass of each porous carbon membrane were summarized in Table 1.

\section{2 Physicochemical analysis of porous carbon}

The macroporous structure of the obtained porous carbon was observed with field-emission scanning electron microscope (FE-SEM, JSM 6700F, JEOL). The nitrogen adsorption/desorption measurements at $77 \mathrm{~K}$ were conducted using a porosimetry analyzer (Tristar 3000, Micrometrics). The specific surface area (SSA) was calculated from the Brunauer-Emmett-Teller (BET) plot of nitrogen adsorption isotherm. The pore size distribution (PSD) was calculated from the Barret-Joyner-Halenda method using the adsorption branch of isotherm. ${ }^{14}$ The surface area of micropores was estimated by $t$-plot method. ${ }^{15)}$ The structural analysis of the prepared carbon was performed using X-ray diffraction (XRD, RINT2000, Rigaku) with $\mathrm{Cu} \mathrm{K} \alpha$ radiation.

\section{3 Electrochemical measurements of porous carbon}

The electrochemical properties of the prepared carbon samples were characterized in a beaker-type cell with two-electrode or three-electrode systems reported elsewhere. ${ }^{16)}$ The porous carbon membrane $(5 \mathrm{~mm} \times 5 \mathrm{~mm}$, ca. $125 \mu \mathrm{m}$ thick) was placed on a copper foil current collector. Note that additives such as binding material and conductive agent were not utilized. A porous polyethylene separator film ( $20 \mu \mathrm{m}$ thick) was placed on the carbon electrode, and a lithium metal foil $\left(4 \mathrm{~cm}^{2}\right)$ was put on the separator. Then, this cell assembly was sandwiched between two polypropylene plates, and they were pressed together by a double-clip and immersed in a beaker filled with an organic electrolyte. In the case of three-electrode system, a reference electrode (small lithium metal piece attached to a nickel wire) was inserted between working electrode and counter electrode. The electrolyte was a mixed solvent of ethylene carbonate (EC) and diethyl carbonate (DEC) (1:1 in volume) containing $1.0 \mathrm{~mol} \mathrm{dm}^{-3} \mathrm{LiClO}_{4}$. The assembled cell was left twelve hours prior to electrochemical measurements, which allowed the electrolyte to penetrate into the pores of carbon electrode. Cyclic voltammetry measurements were carried out at $1 \mathrm{mV} \mathrm{sec}{ }^{-1}$ with an automatic polarization system (HZ-100R, Hokuto Denko). Galvanostatic charge-discharge test was performed with an automatic galvanostat (HJR-110mSM6, Hokuto Denko). Charge-discharge tests were performed as follows; the electrode was cycled at $0.1 \mathrm{C}\left(37.5 \mathrm{~mA} \mathrm{~g}^{-1}\right)$ rate, which corresponded to a current density of $0.075 \mathrm{~mA} \mathrm{~cm}^{-2}$, during initial three cycles, and then the rate capability was evaluated at various current rates of $0.1 \sim 20.0 \mathrm{C}(0.15 \sim 15 \mathrm{~mA}$ $\mathrm{cm}^{-2}$ ). All electrochemical measurements were carried out in an argon-filled glove box at room temperature.

\section{Results and Discussion}

The PSHEMA-silica composite with 3-D structure was used as hard template to prepare the bimodal porous carbon. The large PSHEMA particles were close-packed into an ordered lattice, and the small silica particles were forced to pack closely at the interstices between PSHEMA particles. The PSHEMA particles were interconnected during the heat-treatment at higher than glass transition temperature $\left(T_{\mathrm{g}}\right)$ of $373 \mathrm{~K} .{ }^{17)}$ PSHEMA is a thermally degradable polymer and it decomposes by a depolymerization mechanism. ${ }^{18,19)}$ Indeed, thermogravimetric (TG) analysis of PSHEMA itself under nitrogen atmosphere revealed a clean decomposition of PSHEMA at about $673 \mathrm{~K}$ with $2 \%$ formation of residual material. ${ }^{12)}$ However, several groups reported preparation of carbonaceous materials from polystyrene-based resins. ${ }^{20-22)}$ Although PSHEMA decomposed at around $673 \mathrm{~K}$ into monomers, dimers, trimers, etc., ${ }^{19)}$ some of the decomposed materials were carbonized at the surface of the silica. During the carbonization of the polymer-silica composite, the removal of polymer template created ordered macropores and simultaneously the escaping fragments from decomposing polymer deposited on silica surface in the form of a carbon layer. Furthermore, the removal of silica particles created spherical mesopores. The 
obtained carbon has a 3-D ordered macroporous structure as well as uniform spherical mesopores. TG measurement for the PSHEMA-silica composite revealed that the yield of the carbonized product was $c a .20 \%{ }^{12)}$

Figure 1 shows FE-SEM images of prepared porous carbons. The prepared carbons have large interconnected macropores, and the macropore size $(390 \mathrm{~nm})$ was slightly smaller than the size of used PSHEMA particle $(450 \mathrm{~nm})$. This is due to shrinkage of the macropore during the carbonization process. The walls of the large macropores were composed of small hollow spheres, which were formed by removing the silica particles with HF. The wall of the small spherical hollow carbon was very thin. The ordering degree of the macropores increased as the size of the silica particle decreased. The large silica particles would interfere with polymer particles forming close-packed structure. As reducing the size of silica particle, the polymer particles were accumulated with highly ordered close-packed structure in the composite because the interstices between polymer particles could accommodate the small silica parti-

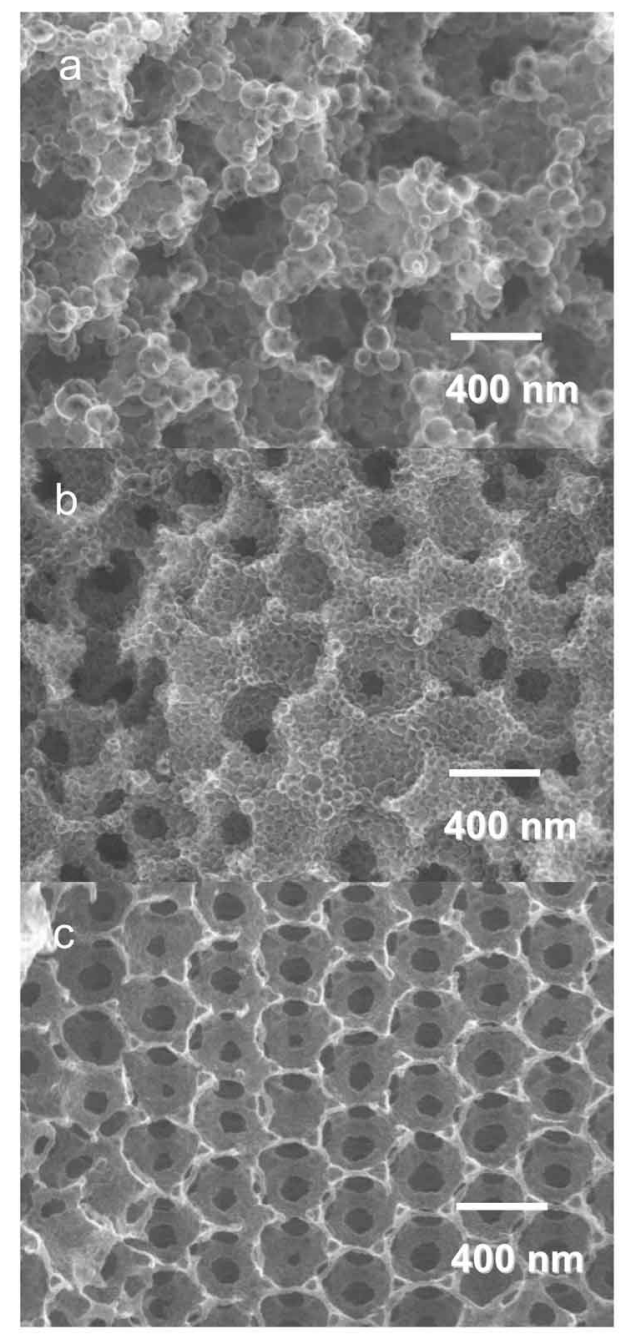

Fig. 1 FE-SEM images of bimodal porous carbons. The silica colloids used as templates for preparation of porous carbons were (a) CS100; 70 $100 \mathrm{~nm}$, (b) CS50; 40 $50 \mathrm{~nm}$, and (c) CS20; $10 \sim 20 \mathrm{~nm}$, respectively. cles with ease. In fact, in the case of the carbon prepared from the composite of PSHEMA-SC20 (Fig. 1c), the inverse opal structure was clearly observed. TG analysis of the porous carbons in air revealed less than $1 \%$ formation of residue, indicating that almost all the silica particles were removed.

The nitrogen adsorption-desorption isotherms of the porous carbons were measured at $77 \mathrm{~K}$. The isotherms and PSD of the porous carbons were reported elsewhere. ${ }^{12)}$ The porous carbon sample $\mathrm{C}$ had a peak centered at $15 \mathrm{~nm}$ in the PSD, which is in good agreement with the size of silica particle used as the template for the mesosized carbon sphere.12) Two other samples had meso/macrosized carbon spheres larger than $40 \mathrm{~nm}$ as observed by FE-SEM (Fig. 1). The SSAs of samples $\mathrm{A}, \mathrm{B}$, and $\mathrm{C}$ estimated by BET method were 492,523 , and $974 \mathrm{~m}^{2} \mathrm{~g}^{-1}$, respectively. The SSA of the porous carbon remarkably increased with decreasing particle size of the silica used as template of the small spherical pores. The surface areas originated from the micropores $(<2 \mathrm{~nm})$ of the samples A, B, and C were estimated by $t$-plot method and found to be 23,25 , and $49 \mathrm{~m}^{2} \mathrm{~g}^{-1}$, respectively. Therefore, it can be said that the surface area of the prepared carbon is mostly due to the mesopores and/or macropores.

Figure 2 shows XRD pattern of the prepared bimodal porous carbon sample A. Other samples showed similar XRD patterns. Three broad diffraction peaks were observed in Fig. 3 centered at 25.5, 43.4, and 78.0 degree, corresponding to (002), (100), and (110) planes, respectively. The interlayer distance $d_{002}$ was $0.3539 \mathrm{~nm}$, which was higher than that of graphite $(0.3354 \mathrm{~nm})$, indicating that the prepared material was disordered carbon and involved turbostratic structures. ${ }^{23)}$ The microcrystallite sizes in $a$-axis $\left(L_{a}\right)$ and $c$-axis $\left(L_{c}\right)$ directions were estimated using Scherrer's equation from the full width at half maximum (FWHM) of the XRD peaks of (100) and (002), respectively. The values of $d_{002}, L_{a}$, and $L_{c}$ are summarized in Table 1.

Figure 3 shows cyclic voltammograms (CVs) of the porous carbon sample A. Cyclic voltammetry was performed using two-electrode configuration. The initial potential (pzc: point of zero charge) of the porous carbon electrode before $\mathrm{CV}$ measurements was $c a .3 .0 \mathrm{~V}$ vs. $\mathrm{Li} / \mathrm{Li}^{+}$. A large irreversible cathodic current was

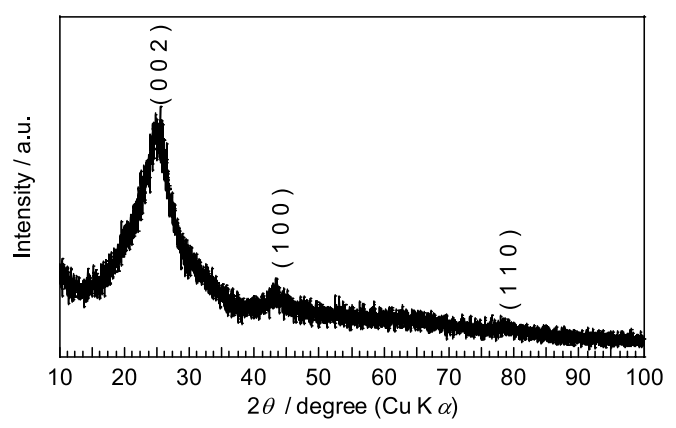

Fig. 2 XRD pattern of bimodal porous carbon prepared using silica colloid CS100. 
Table 1 Characteristics of porous carbon membranes. BET surface area determined by nitrogen adsorption/desorption measurements and crystallite parameters estimated from XRD.

\begin{tabular}{ccccccc}
\hline $\begin{array}{c}\text { sample } \\
\text { name }\end{array}$ & $\begin{array}{c}\text { thickness } \\
/ \mu \mathrm{m}\end{array}$ & $\begin{array}{c}\text { mass per unit area } \\
/ \mathrm{mg} \mathrm{cm}^{-2}\end{array}$ & $\begin{array}{c}\text { BET-SSA } \\
/ \mathrm{m}^{2} \mathrm{~g}^{-1}\end{array}$ & $\begin{array}{c}d_{002} \\
/ \mathrm{nm}\end{array}$ & $\begin{array}{c}L_{a} \\
/ \mathrm{nm}\end{array}$ & $\begin{array}{c}L_{c} \\
/ \mathrm{nm}\end{array}$ \\
\hline $\mathrm{A}$ & 130 & 1.9 & 492 & 0.3539 & 4.085 & 1.998 \\
$\mathrm{~B}$ & 120 & 2.0 & 523 & 0.3558 & 4.083 & 2.048 \\
$\mathrm{C}$ & 125 & 2.4 & 974 & 0.3587 & 4.165 & 2.037 \\
\hline
\end{tabular}

observed in the potential range of $1.0 \sim 0.0 \mathrm{~V}$ vs. $\mathrm{Li} / \mathrm{Li}^{+}$ during the first cycle, indicating formation of a solid electrolyte interphase (SEI) due to the decomposition of the electrolytes. ${ }^{24)}$ The cathodic current decreased in 2nd and 3rd potential cycles, because the SEI on the carbon suppressed further decomposition of the electrolyte. The current responses of the porous carbon electrode during both cathodic and anodic scans showed monotonous features in the potential range of $0.0 \sim 1.5 \mathrm{~V}$. This $\mathrm{CV}$ profile is attributed to intercalation/deintercalation of $\mathrm{Li}$ into/from the carbon structure. The continuous $\mathrm{Li}$ insertion in the wide potential range without significant structural change is typical for disordered carbons. ${ }^{25)}$

The prepared carbon has the complicated porous structure and high specific surface area; therefore, it is important to evaluate the double-layer capacitance of the carbon for further insight into the electrochemical behavior of the electrode. In order to evaluate the double-layer capacitance $\left(C_{d l}\right)$ of the carbon electrode, ac impedance measurements were performed for the electrode using three-electrode cell. Prior to impedance measurement, the carbon electrode was galvanostatically charged and discharged for three cycles between 3.0 and $0.0 \mathrm{~V}$ vs. $\mathrm{Li} / \mathrm{Li}^{+}$at a current density of $37.5 \mathrm{~mA} \mathrm{~g}{ }^{-1}$ to form SEI on the carbon surface. The impedance measurement was carried out at the electrode potential of 2.5 $\mathrm{V}$ vs. $\mathrm{Li} / \mathrm{Li}^{+}$, where $\mathrm{Li}$ intercalation/deintercalation did not take place and the $C_{d l}$ could be estimated without

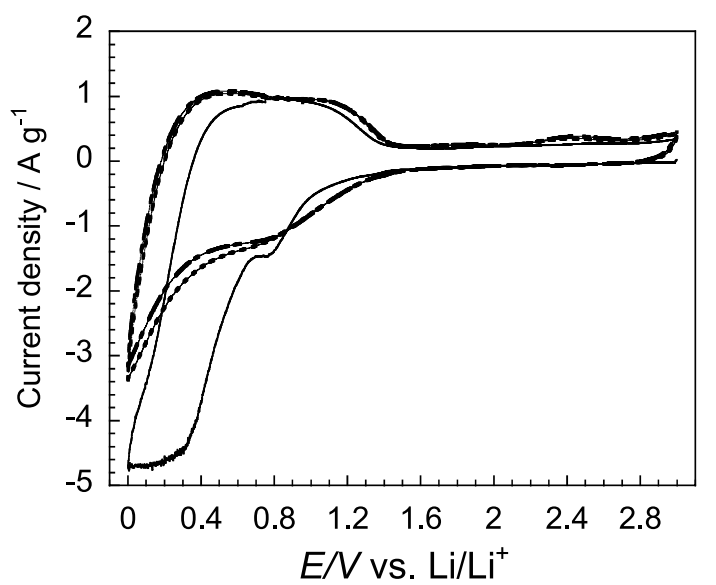

Fig. 3 Cyclic voltammograms of bimodal porous carbon prepared using silica colloid CS100. Solid, dash and dash dot lines are first, second, and third cycle, respectively. The electrolyte was $1 \mathrm{M} \mathrm{LiClO}_{4} / \mathrm{EC}+\mathrm{DEC}$, and the scan rate was $1 \mathrm{mV} \mathrm{sec}{ }^{-1}$. influence of faraday process. Figure 4 shows cole-cole plots of the carbon electrodes measured at $2.5 \mathrm{~V}$ in the frequency range from $10 \mathrm{mHz}$ to $100 \mathrm{kHz}$. In the high frequency range, depressed arc was seen, which was attributed to the porous structure of the electrode. The current distribution is non-uniform in the high frequencies due to the porous structure, which may be explained by some complicated equivalent circuit model. ${ }^{26,27)}$ In the low frequency range, the imaginary part of the impedance increased as decreasing frequency, indicating the blocking electrode behavior. The $C_{d l}$ of the carbon was estimated from the value of imaginary part $\left(Z_{i m}\right)$ of impedance measured at the lowest frequency $(f=10 \mathrm{mHz})$ using following equation (1).

$$
C_{d l}=-1 /\left(2 \pi f Z_{\text {im }}\right)
$$

The estimated double-layer capacitances of samples A, B, and $\mathrm{C}$ were $17.7,21.7$, and $40.5 \mathrm{~F} \mathrm{~g} \mathrm{~g}^{-1}$, respectively. The double-layer capacitance of the porous carbon was almost proportional to the SSA.

Figure 5 shows charge and discharge curves of the bimodal porous carbons measured at $0.1 \mathrm{C}$ rate. Chargedischarge tests were carried out using two-electrode cell. A potential plateau was observed at $0.9 \mathrm{~V}$ vs. $\mathrm{Li} / \mathrm{Li}^{+}$in the first charge curve, caused by the reduction of elec-

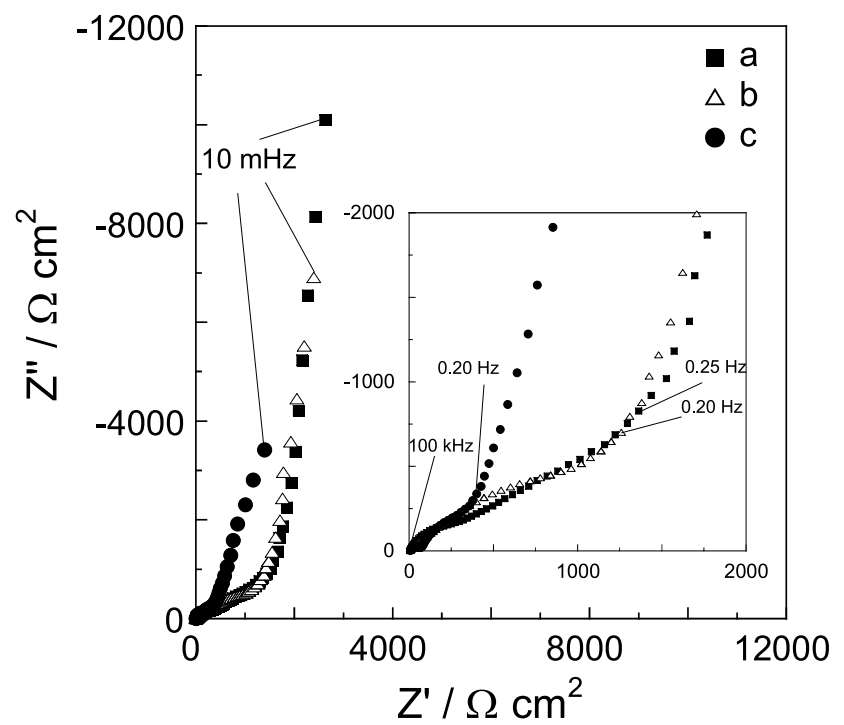

Fig. 4 Nyquist plots of porous carbon electrodes measured in $1 \mathrm{M} \mathrm{LiClO}_{4} / \mathrm{EC}+\mathrm{DEC}$ at the electrode potential of $2.5 \mathrm{~V}$ vs. $\mathrm{Li} / \mathrm{Li}^{+}$. The silica colloids used as templates were CS100 (a), CS50 (b), and CS20 (c), respectively. 
trolytes and formation of SEI film on the porous carbon electrode. The formation of SEI on the surface of carbon electrode brought about large irreversible capacity of the first cycle. The irreversible capacity increased with increasing SSA of porous carbon electrode, indicating that the large SSA provides large electrochemical interface for irreversible decomposition of electrolyte. ${ }^{24}$ The irreversible capacity decreased dramatically in the subsequent cycles, and the coulombic efficiency was higher than $95 \%$. In the subsequent cycles, both of charge and discharge profiles were monotonous, which were in good agreement with the profile of CV (Fig. 4). The reversible capacities of porous carbon samples $A, B$, and $\mathrm{C}$ were 662 , 811, and $1000 \mathrm{~mA} \mathrm{~h} \mathrm{~g}{ }^{-1}$, respectively, which were higher than the theoretical capacity of graphite $\left(372 \mathrm{~mA} \mathrm{~h} \mathrm{~g} \mathrm{~g}^{-1}\right)$. It is well known that some kinds of disordered carbons show larger capacities than $372 \mathrm{~mA} \mathrm{~h}$ $\mathrm{g}^{-1,28,29)}$ although the charge and discharge mechanism is not clear yet. It has been reported that the microstructures such as crystallite sizes give significant effects on reversible capacity. ${ }^{30)}$ Although the crystallite sizes of three carbon samples were almost same as shown in Table 1, the reversible capacity of the bimodal porous carbon increased as increasing the BET specific surface area. The contribution of double-layer capacitance to the charge and discharge capacity was very small. The $C_{d l}$ of the sample $\mathrm{C}$ was $40.5 \mathrm{~F} \mathrm{~g}^{-1}$, which corresponded to a capacity of $34 \mathrm{~mA} \mathrm{~h} \mathrm{~g}^{-1}$ calculated on the assumption that the $C_{d l}$ did not depend on the electrode potential. These results indicated that not only the Li-insertion into the solid but also the surface electrochemical reaction contributed to the charge and discharge capacities. The adsorption of atomic Li might take place reversibly on the carbon surface. Another possible reason for the effect of specific surface area upon the discharge capacity was the pseudocapacitance of the surface functional groups on the carbon surface. However, further investigations are needed to understand the charge and discharge mechanism of the porous carbon.

The charge and discharge curves of the porous carbon electrodes were measured at various rates of $0.2 \sim 20 \mathrm{C}$. The charge and discharge capacities decreased as increasing current density. The dependence of the discharge capacity on the current density is shown in Fig. 6. At high current densities, the charging process was ter- minated before the maximum capacity was attained. This is caused by the internal resistance and overpotential for Li-intercalation.

The discharge capacities of the porous carbons can be converted to the capacitances $\left(C_{t}\right)$ using following equation (2).

$$
C_{t}=Q / \Delta V
$$

Here, $Q$ is the discharge capacity of the electrode, and the $\Delta V$ is the potential difference of the carbon electrode before and after discharge $(\Delta V=3 \mathrm{~V})$. The calculated capacitances of the porous carbons were higher than 800 $\mathrm{F} \mathrm{g}^{-1}$ at very low current density of $37.5 \mathrm{~mA} \mathrm{~g}^{-1}(0.075$ $\mathrm{mA} \mathrm{cm}^{-2}$ ). As discussed above, almost all the capacitance was due to the redox capacitance, i.e. Li-intercalation capacitance of the carbon electrode. The capacitance decreased as increasing current density. However, the capacitance of the sample $\mathrm{C}$ was as high as $360 \mathrm{~F} \mathrm{~g}^{-1}$ even at a high current density of $7.4 \mathrm{~A} \mathrm{~g}^{-1}\left(15 \mathrm{~mA} \mathrm{~cm}{ }^{-2}\right)$. It was considered that the large SSA and macro/mesoporous structure were effective in achieving high capaci-

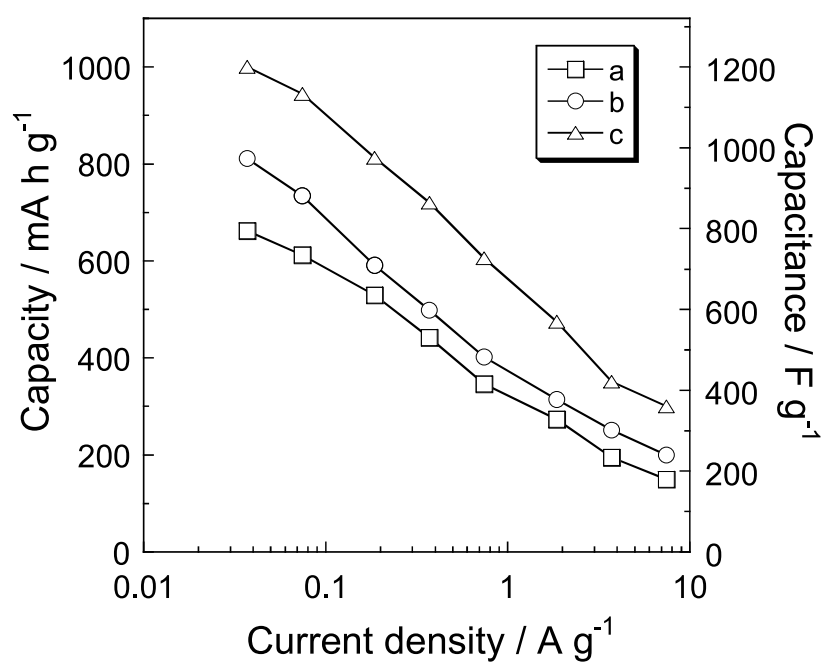

Fig. 6 Plots of discharge capacity and its calculated capacitance of porous carbon electrodes as a function of discharge current density. The silica colloids used as templates were CS100 (a), CS50 (b), and CS20 (c), respectively.

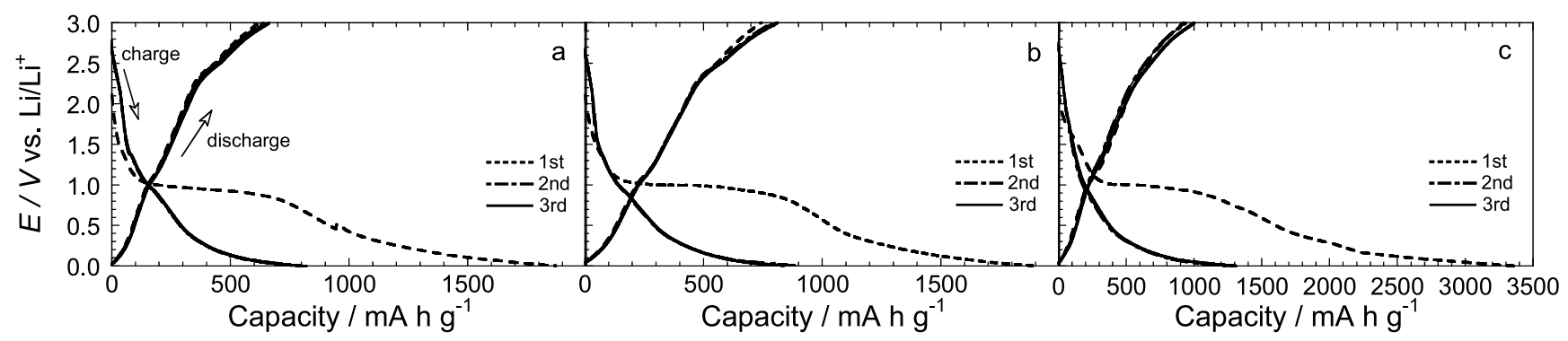

Fig. 5 Charge and discharge curves of porous carbon electrodes measured in $1 \mathrm{M} \mathrm{LiClO}_{4} / \mathrm{EC}+\mathrm{DEC}$ at $0.1 \mathrm{C}\left(37.5 \mathrm{~mA} \mathrm{~g}^{-1}\right)$. Dash, dash dot, and solid line are first, second, and third cycle, respectively. The silica colloids used as templates were CS100 (a), CS50 (b), and CS20 (c), respectively. 
tance even at high current density. The large surface area provides large electrochemical interface for Li-intercalation. The 3-D macroporous structure may be useful for facile mass transfer of ion species within the porous electrode, which reduces the internal resistance of the electrode. The wall thickness of the porous carbon is the diffusion length of $\mathrm{Li}$ in the solid, therefore, very thin wall is also useful in reducing the resistance.

\section{Conclusion}

Three-dimensionally ordered macroporous carbons having walls composed of hollow mesosized spheres were prepared by heat treatment of PSHEMA colloidal crystal template with silica particles, followed by HF treatment to remove silica. Macropore size was $390 \mathrm{~nm}$ and mesopore size could be controlled by silica size. The porous structures of the prepared carbons were mainly composed of interconnected macropores and spherical mesopores.

Cyclic voltammetry revealed that lithium intercalation/deintercalation occurred into/from the prepared carbons. Though the irreversible capacity of the first cycle is a serious problem for a practical use, it can be solved by pre-lithiation of the carbon prior to use. From ac impedance measurements and charge-discharge tests, it was found that contribution of double-layer capacitance to the whole discharge capacity was very small and the most of discharge capacity was due to the lithium intercalation. The charge and discharge capacities were increased with increasing BET surface area of the carbon. The rate capability of the sample prepared using CS20 showed a large capacitance of $360 \mathrm{~F} \mathrm{~g}^{-1}$ at a high current of $7.4 \mathrm{~A} \mathrm{~g} \mathrm{~g}^{-1}$ because of the unique structure of the bimodal porous carbon.

\section{Acknowledgements}

The authors thank Prof. Hideki Masuda (Tokyo Metropolitan University) for his kind help in taking FESEM photographs and gratefully acknowledge fruitful discussion with Prof. Masayoshi Watanabe (Yokohama National University).

\section{References}

1) G. G. Amatucci, F. Badway, A. Du Pasquier, and T. Zheng, J. Electrochem. Soc., 148, A930 (2001).

2) A. Du Pasquier, I. Plitz, S. Menocal, and G. Amatucci, J. Power Sources., 115, 171 (2003).

3) A. Du Pasquier, I. Plitz, J. Gural, F. Badway, and G. G. Amatucci, J. Power Sources., 136, 160 (2004).

4) A. Yoshino, T. Tsubata, M. Shimoyamada, H. Satake, Y. Okano, S. Mori, and S. Yata, J. Electrochem. Soc., 151, A2180 (2004).

5) T. Aida, K. Yamada, and M. Morita, Electrochem. SolidState Lett., 9, A534 (2006).
6) N. Ando, S. Tasaki, T. Fujii, K. Kojima, K. Matsui, O. Hatozaki, Y. Hato, and H. Shibuya, 46th Battery Symposium in Japan Abstract, 1C12 (2005).

7) S. Tasaki, N. Ando, R. Takahata, A. Shirakami, K. Matsui, H. Taguchi, M. Nagai, O. Hatozaki, Y. Hato, and H. Shibuya, 46th Battery Symposium in Japan Abstract, $1 \mathrm{C} 13$ (2005).

8) T. Tsubata, M. Shimoyamada, A. Yoshino, H. Satake, S. Mori, and S. Yata, 46th Battery Symposium in Japan Abstract, 1C25 (2005).

9) S. Shiraishi, H. Kurihara, L. Shi, T. Nakayama, and A. Oya, J. Electrochem. Soc., 149, A855 (2002).

10) A. B. Fuertes, F. Pico, and J. M Rojo, J. Power Sources, 133, 329 (2004).

11) Z. Li and M. Jaroniec, J. Am. Chem. Soc., 123, 9208 (2001).

12) S. W. Woo, K. Dokko, K. Sasajima, T. Takei, and K. Kanamura, Chem. Commun., 20064099.

13) C. E. Reese and S. A. Asher, J. Colloid Interface Sci., 41, 248 (2002).

14) E. P. Barrett, L. G. Joyner, and P. P. Halenda, J. Am. Chem. Soc., 73, 373 (1951).

15) F. Rouquerol, and J. Rouquerol, and K. Sing, Adsorption by Powders and Porous Solids: Principles, Methodology and Applications, Academic Press, London, (1999).

16) K. Dokko. H. Nakano, and K. Kanamura, Electrochemistry, 75, 385 (2007).

17) B. Gates, S. H. Park, and Y. Xia, Adv. Mater., 12, 653 (2000).

18) L. Reich and S. S. Stivala, Elements of Polymer Degradation, McGraw Hill, New York (1971).

19) E. Jakab, M. Blazso, and O. Faix, J. Anal. Appl. Pyrolysis, 58-59, 49 (2001).

20) D. Hines, A. Bagreev, and T. J. Bandosz, Langmuir, 20, 3388 (2004).

21) C. N. Mbileni, F. F. Prinsloo, M. J. Witcomb, and N. J. Coville, Carbon, 44, 1476 (2006).

22) L. Li, H. Song, and X. Chen, Carbon, 44, 587 (2006).

23) R. L. McCreery, Electroanalytical Chemistry (Ed. A. J. Bard), Vol. 17, Marcel Dekker, New York, NY, p. 221, (1991).

24) Z. Ogumi and M. Inaba, Bull. Chem. Soc. Jpn., 71, 521 (1998).

25) J. R. Dahn, A. K. Sleigh, H. Shi, J. N. Reimers, Q. Zhong, and B. M. Way, Electrochim. Acta, 38, 1179 (1993).

26) H. Keiser, K. D. Beccu, and M. A. Gutjahr, Electrochim. Acta, 21, 539 (1976).

27) M. Itagaki, S. Suzuki, I. Shitanda, K. Watanabe, and H. Nakazawa, J. Power Sources, 164, 415 (2007).

28) T. Zheng, Y. Liu, E. W. Fuller, S. Tseng, U. von Sacken, and J. R. Dahn, J. Electrochem. Soc., 142, 2581 (1995).

29) T. Zheng, J. S. Xue, and J. R. Dahn, Chem. Mater., 8, 289 (1996).

30) A. Mabuchi, K. Tokumitsu, H. Fujimoto, and T. Kasuh, J. Electrochem. Soc., 142, 1041 (1995). 